\title{
Favipiravir versus other antiviral or standard of care for COVID-19 treatment: a rapid systematic review and meta-analysis
}

\author{
Dhan Bahadur Shrestha ${ }^{1} \mathbb{0}$, Pravash Budhathoki ${ }^{\circledR}$, Sitaram Khadka ${ }^{3^{*}} \mathbb{0}$, Prajwol Bikram Shah ${ }^{4} \mathbb{D}$, \\ Nisheem Pokharel ${ }^{5}$ and Prama Rashmi ${ }^{4}$
}

\begin{abstract}
Background: The COVID-19 causing coronavirus is an enveloped RNA virus that utilizes an enzyme RNA dependent RNA polymerase for its replication. Favipiravir (FVP) triphosphate, a purine nucleoside analog, inhibits that enzyme. We have conducted this systematic review and meta-analysis on efficacy and safety of the drug FVP as a treatment for COVID-19.

Methods: Databases like Pubmed, Pubmed Central, Scopus, Embase, Google Scholar, preprint sites, and clinicaltirals. gov were searched. The studies with the standard of care (SOC) and FVP as a treatment drug were considered as the treatment group and the SOC with other antivirals and supportive care as the control group. Quantitative synthesis was done using RevMan 5.4. Clinical improvement, negative conversion of reverse transcription-polymerase chain reaction (RT-PCR), adverse effects, and oxygen requirements were studied.
\end{abstract}

Results: We identified a total of 1798 studies after searching the electronic databases. Nine in the qualitative studies and four studies in the quantitative synthesis met the criteria. There was a significant clinical improvement in the FVP group on the 14th day compared to the control group (RR 1.29, 1.08-1.54). Clinical deterioration rates were less likely in the FVP group though statistically not significant (OR $0.59,95 \% \mathrm{Cl} 0.30-1.14$ ) at the endpoint of study (7-15 days). The meta-analysis showed no significant differences between the two groups on viral clearance (day 14: RR 1.06,95\% Cl 0.84-1.33), non-invasive ventilation or oxygen requirement (OR $0.76,95 \% \mathrm{Cl} 0.42-1.39$ ), and adverse effects (OR $0.69,0.13-3.57$ ). There are 31 randomized controlled trials (RCTs) registered in different parts of the world focusing FVP for COVID-19 treatment.

Conclusion: There is a significant clinical and radiological improvement following treatment with FVP in comparison to the standard of care with no significant differences on viral clearance, oxygen support requirement and side effect profiles.

Keywords: Antiviral agents, COVID-19, COVID-19 drug treatment, Favipiravir, Severe acute respiratory syndrome coronavirus-2

*Correspondence: sitaramkhadka5693@gmail.com; sitaram.khadka@naihs. edu.np

${ }^{3}$ Shree Birendra Hospital, Nepalese Army Institute of Health Sciences, Kathmandu, Nepal

Full list of author information is available at the end of the article

\section{Background}

The outbreak of a novel coronavirus named severe acute respiratory syndrome coronavirus-2 (SARS-CoV-2) started in Wuhan, China, in late December 2019. The COVID-19 caused by such a virus was declared a global pandemic by WHO on 11th of March 2020 [1]. The number of cases and mortality that the virus has claimed

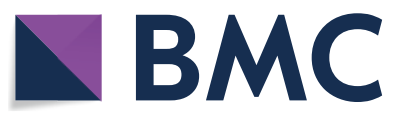

(c) The Author(s) 2020. This article is licensed under a Creative Commons Attribution 4.0 International License, which permits use, sharing, adaptation, distribution and reproduction in any medium or format, as long as you give appropriate credit to the original author(s) and the source, provide a link to the Creative Commons licence, and indicate if changes were made. The images or other third party material in this article are included in the article's Creative Commons licence, unless indicated otherwise in a credit line to the material. If material is not included in the article's Creative Commons licence and your intended use is not permitted by statutory regulation or exceeds the permitted use, you will need to obtain permission directly from the copyright holder. To view a copy of this licence, visit http://creativecommons.org/licenses/by/4.0/. The Creative Commons Public Domain Dedication waiver (http://creativecommons.org/publicdomain/zero/1.0/) applies to the data made available in this article, unless otherwise stated in a credit line to the data. 
around the globe is astronomical. As of 26 August 2020, the number of confirmed cases and deaths reported has reached 23,752,965 and 815,038 respectively [2]. This virus is getting transmitted mainly via respiratory tracts through droplets or respiratory secretions. The disease is characterized by asymptomatic to flu-like mild respiratory symptoms including shortness of breath (SOB) leading to pneumonia, acute respiratory distress syndrome (ARDS), and even multiple organ dysfunction in severe cases [3]. The coronavirus is an enveloped, non-segmented positive-sense RNA virus that utilizes an enzyme RNA dependent RNA polymerase (RdRp) for its replication which could be a potential target for the treatment development [4].

The road to discovering the effective prophylaxis and treatment is still an ongoing process. Numerous trials of medications of different categories have been conducted but none have succeeded to show promising results for effective treatment $[5,6]$. Some of the repurposed drugs like remdesivir are being utilized along with supportive care for the management of COVID-19 in different clinical settings.

Favipiravir (FVP) triphosphate, a purine nucleoside analog, competitively inhibits the enzyme RdRp. It has shown activity against influenza viruses, RNA viruses associated with viral hemorrhagic fever, and even against SARS-CoV-2 in vitro [7]. The evidence regarding FVP is relatively low as there have only been a handful of studies regarding its efficacy and safety among COVID-19 patients. We conducted this systematic review and metaanalysis to evaluate the efficacy and safety of the drug FVP as a treatment for COVID-19.

\section{Objective}

To determine the clinical improvement following the treatment with FVP in the cases of COVID-19, duration to attaining and percentage that attained negative conversion of RT-PCR following the treatment, adverse effects that were seen during the treatment, oxygen and mechanical ventilation requirements following the treatment.

\section{Methods}

We used PRISMA for the systematic review of available literature [8].

\section{Criteria for considering studies for this review Types of studies}

We included studies that were done to determine the safety and efficacy of FVP along with the standard of care (SOC) for COVID-19 diagnosed cases based on guidelines in comparison to the control group receiving standard of care alone. We only included the case series with more than 5 patients, randomized controlled trials, controlled clinical trials, prospective and retrospective studies where FVP was used in the management of COVID-19 patients in the qualitative analysis. Only the studies with both the treatment and the control groups were included in quantitative synthesis.

\section{Types of participants}

The studies had patients with COVID-19 diagnosed as per guidelines who were enrolled either in FVP and SOC compared to standard of care alone in quantitative analysis.

\section{Types of interventions}

FVP along with the SOC was taken in the treatment arm and SOC alone in the control arm. SOC included other antivirals, respiratory support, antibiotics, immunomodulators, and herbal medicines.

\section{Types of outcome measures}

Our outcomes of interest were clinical improvements following the treatment with FVP in cases of COVID-19; negative seroconversion of RT-PCR; adverse effects that were seen during the treatment; oxygen and mechanical ventilation requirements.

\section{Outcomes}

The parameters for clinical improvements were symptomatic and radiological improvements (in CT scan), and clinical deterioration at 7 and 14 days after treatment between the treatment and control group. We also compared overall adverse effects that had occurred during the treatment and respiratory support requirements between the treatment and control groups. We also compared the time to negative RT-PCR and the percentage of negative RT-PCR at day 7 and 14 following treatment.

\section{Search methods for identification of studies}

Studies were independently screened by two reviewers (DBS and $\mathrm{PB}$ ) using COVIDENCE and data were extracted for both quantitative and qualitative synthesis. The conflicts were resolved by taking the opinion of the third reviewer (NP). Assessment of biases and crosschecking of the selected studies were done by another reviewer (SK).

\section{Electronic searches}

We have included the electronic search strategy in Additional file 1 .

\section{Data collection and analysis}

Databases like Pubmed, Pubmed central, Scopus, Embase, Google Scholar, bioRxiv, medRxiv, and 
clinicaltirals.gov were searched until 20th August, 2020. We decided to include the preprints because the studies on FVP are actively ongoing with very few papers published in academic journals. We extracted data for quantitative synthesis and analyzed it using RevMan 5.4.

\section{Selection of studies}

We included RCTs, controlled clinical trials, prospective and retrospective observational studies for all case series with more than 5 patients for our qualitative analysis in which FVP was used in the treatment of COVID-19 patients with sufficient details on outcomes. We included studies with the treatment groups in which patients received FVP and SOC in the treatment group and SOC alone in the control group for quantitative analysis. Studies lacking control groups were excluded in the quantitative analysis. We excluded studies where the outcomes of the patients receiving favipiravir were not properly defined. Case reports, reviews, protocols, in-vitro studies, and letters to editors were also excluded.

\section{Data extraction and management}

We evaluated the quality of the studies and included the outcome of interest in the quantitative synthesis.

\section{Assessment of risk of bias in included studies}

We used the Cochrane risk of bias (ROB) tool to analyze the risk of bias shown in Fig. 1 [9]. We used the NHLBI (National Heart, Lung, and Blood Institute) quality assessment tools (Additional file 2) to assess the risk of bias in observational studies and case series (Table 1) [10]. We used the RevMan 5.4 for the creation of risk-ofbias plots.

\section{Assessment of heterogeneity}

We assessed the heterogeneity using the I-squared $\left(\mathrm{I}^{2}\right)$ test. We used the Cochrane Handbook for Systematic Reviews of Interventions for interpretation of $\mathrm{I}^{2}$ test done as follows based on " $0-40 \%$ : might not be important; $30 \%$ to $60 \%$ may represent moderate heterogeneity; $50 \%$ to $90 \%$ : may represent substantial heterogeneity; $75 \%$ to 100\%: considerable heterogeneity [16]. The importance of the observed value of $\mathrm{I}^{2}$ depends on (1) magnitude and direction of effects and (2) strength of evidence for heterogeneity (e.g. $P$ value from the chi-squared test, or a confidence interval for $\mathrm{I}^{2}$ )."

\section{Assessment of reporting biases}

We assessed the reporting biases through predetermined outcome reporting documentation.

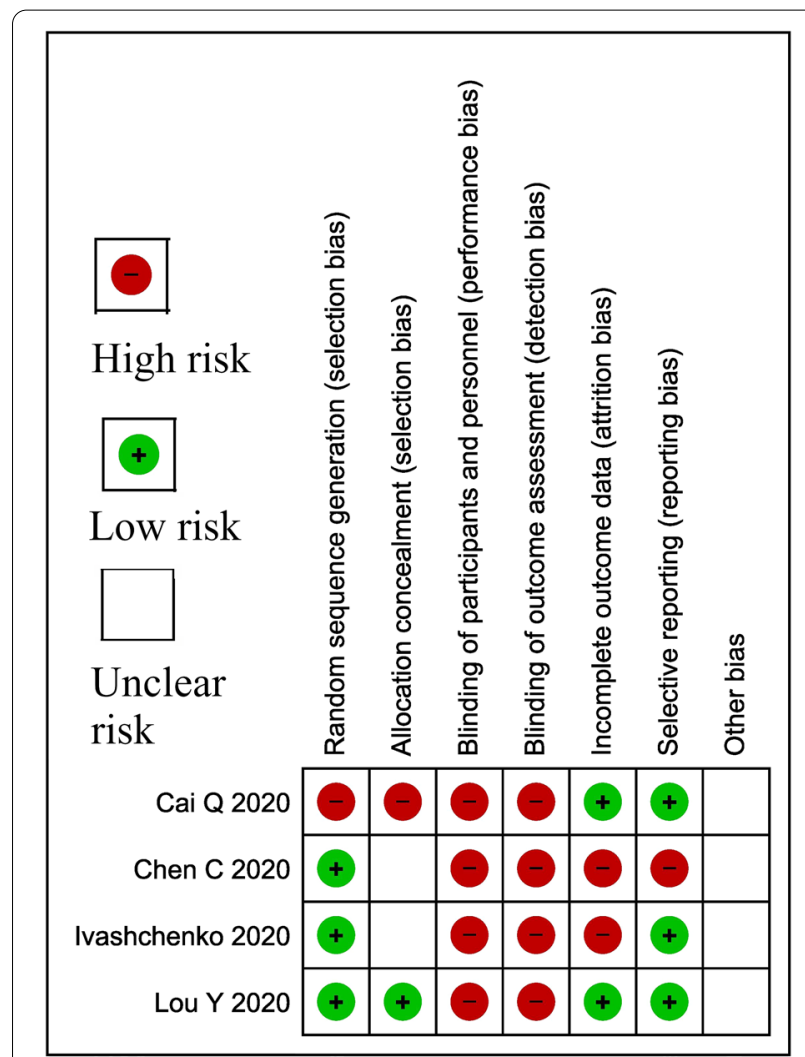

Fig. 1 Risk of bias assessment of trials

\section{Data synthesis}

We did a statistical analysis using RevMan 5.4 software. We used Risk Ratio (RR)/ Odds Ratio (OR) for outcome estimation whenever appropriate with $95 \%$ Confidence Interval (CI). We used the fixed/randomeffects model as per the heterogeneities. We assessed the heterogeneity using the $\mathrm{I}^{2}$ test. We analyzed the mean differences among the two groups for the duration of viral clearance using the median, sample size, and interquartile range whenever the means and standard deviations were not provided in the study [17].

\section{Subgroup analysis and investigation of heterogeneity}

In the case of heterogeneity, we tried the inverse variance, random-effect model. We then ran an analysis excluding non-randomized study to evaluate their impact on the overall result wherever appropriate. We presented Forest plots to visualize the degree of variation between studies. 
Table 1 NHLBI assessment of observational studies and case series

\begin{tabular}{lllll}
\hline Study & Study type & Score & Percentage & Quality \\
\hline Çalik BaŞaran et al. [11] & Prospective observational study & $10 / 14$ & 71.4 & Good \\
Doi et al. [12] & Case series & $6 / 9$ & 66.66 & Good \\
Irie et al. [13] & Case series & $6 / 9$ & 66.66 & Good \\
Rattanaumpawan et al. [14] & Retrospective observational study & $8 / 14$ & 57.1 & Fair \\
Yamamura et al. [15] & Prospective single center study & $10 / 14$ & Good
\end{tabular}

Good if they fulfilled $60-100 \%$ of the tool items, fair if $50-59 \%$ or Poor if $0-49 \%$

\section{Sensitivity analysis}

For sensitivity analysis, we examined the effect of study based on their type (RCT and non-RCT) by excluding non-RCT studies when appropriate and re-running the analysis to find any differences.

\section{Results}

Qualitative synthesis

We identified a total of 1798 studies after searching the electronic databases. After the removal of 462 duplicates, the title and abstracts of 1336 studies were screened. We

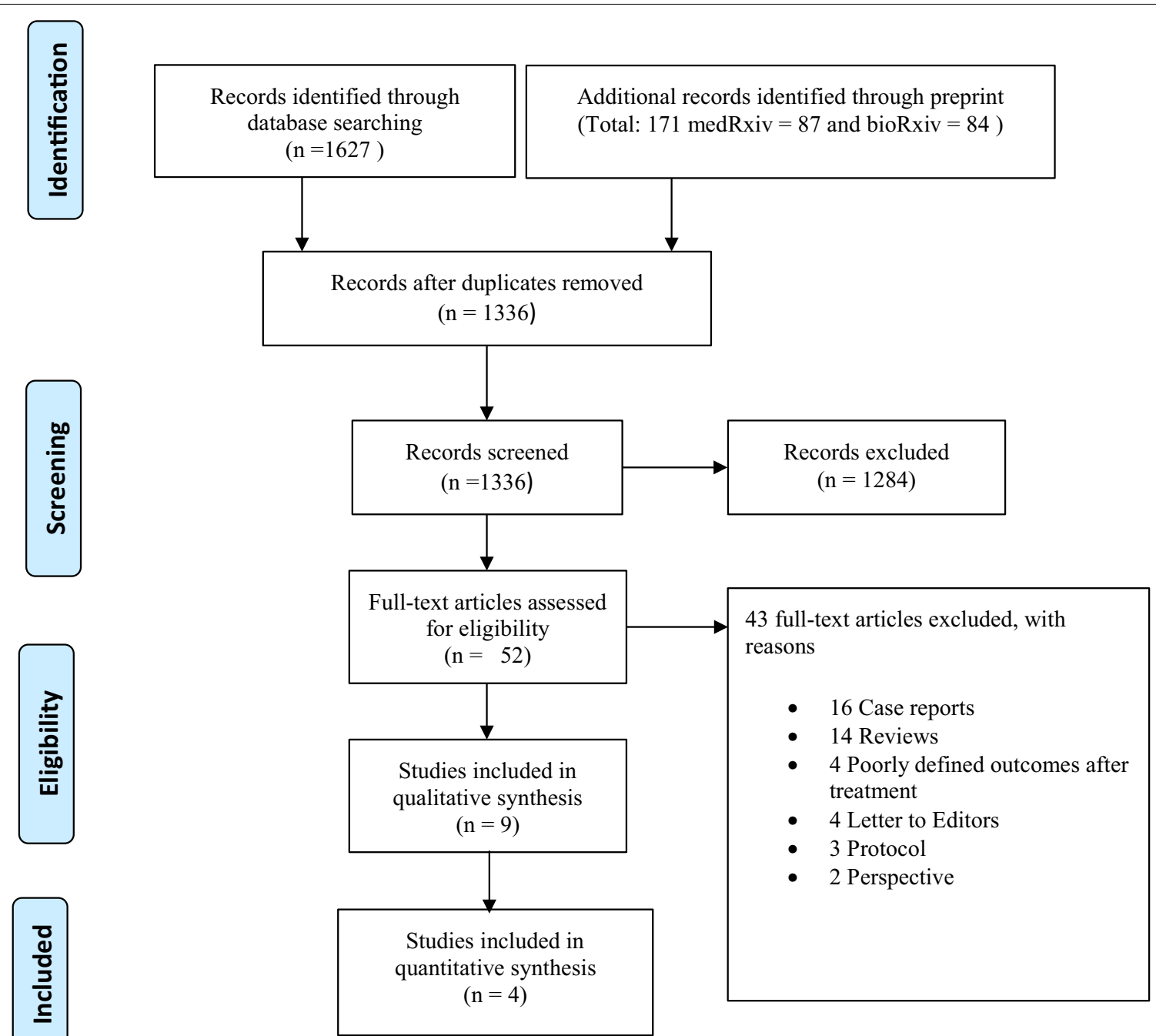

Fig. 2 PRISMA flow chart 


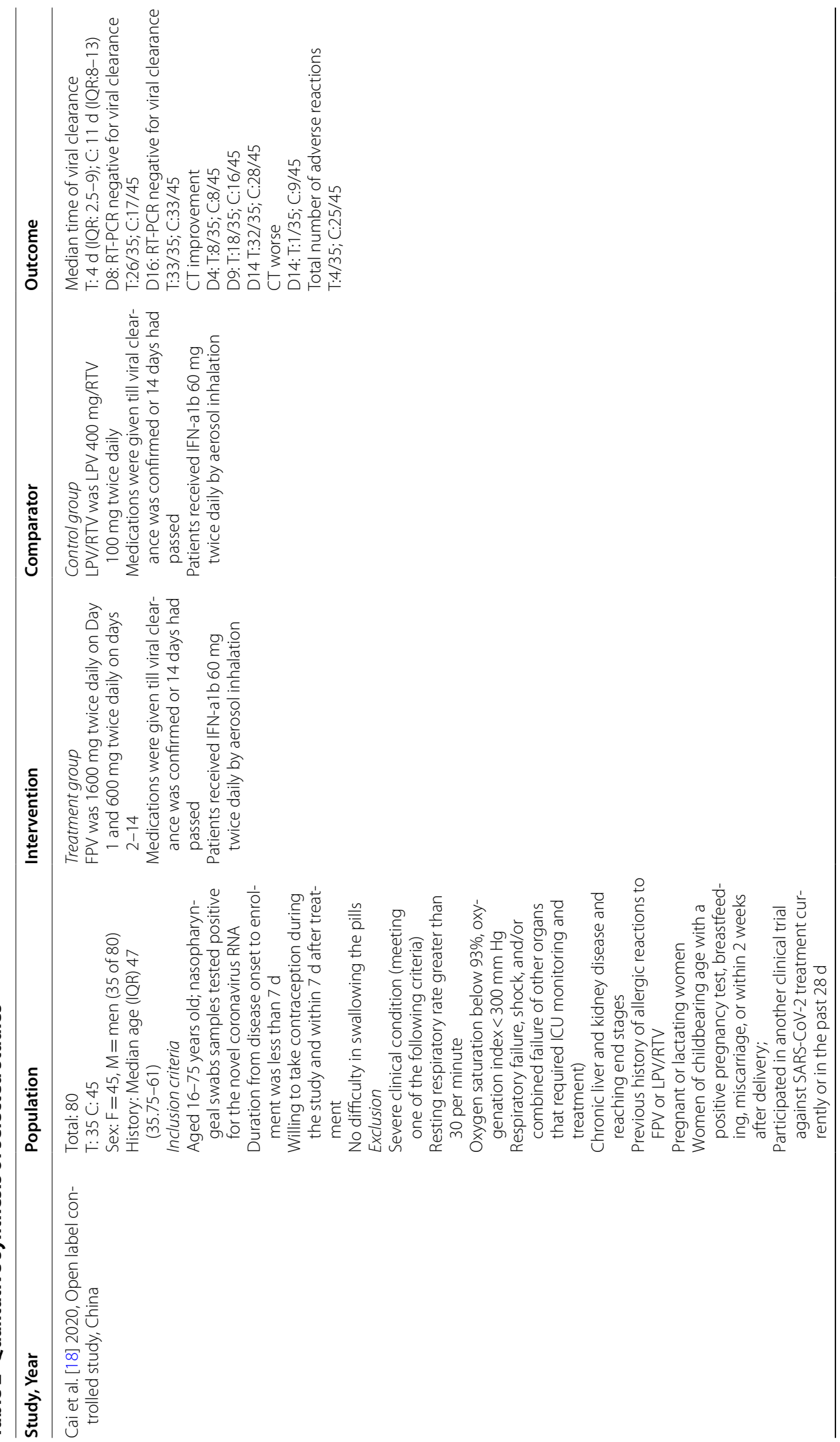




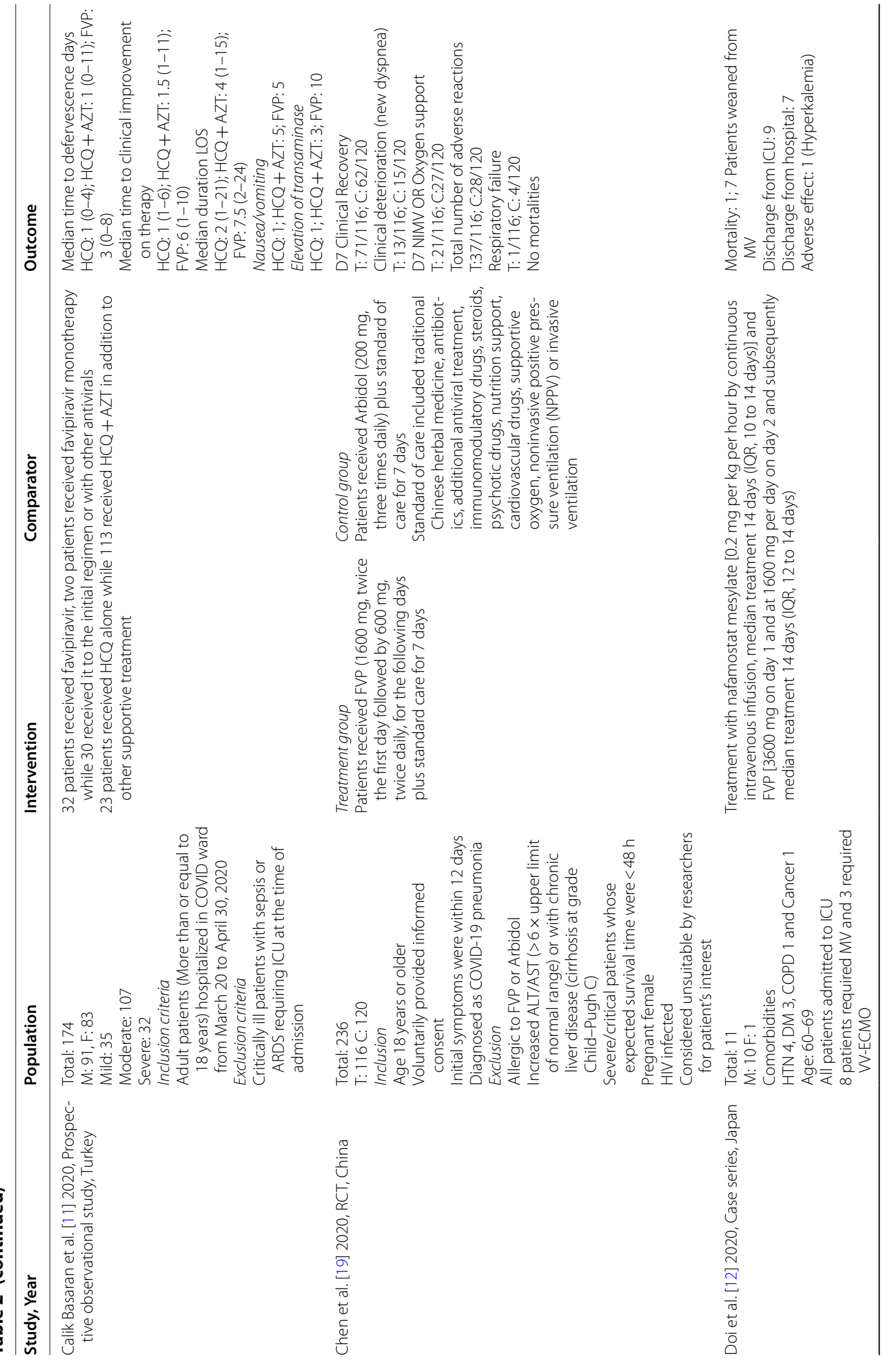




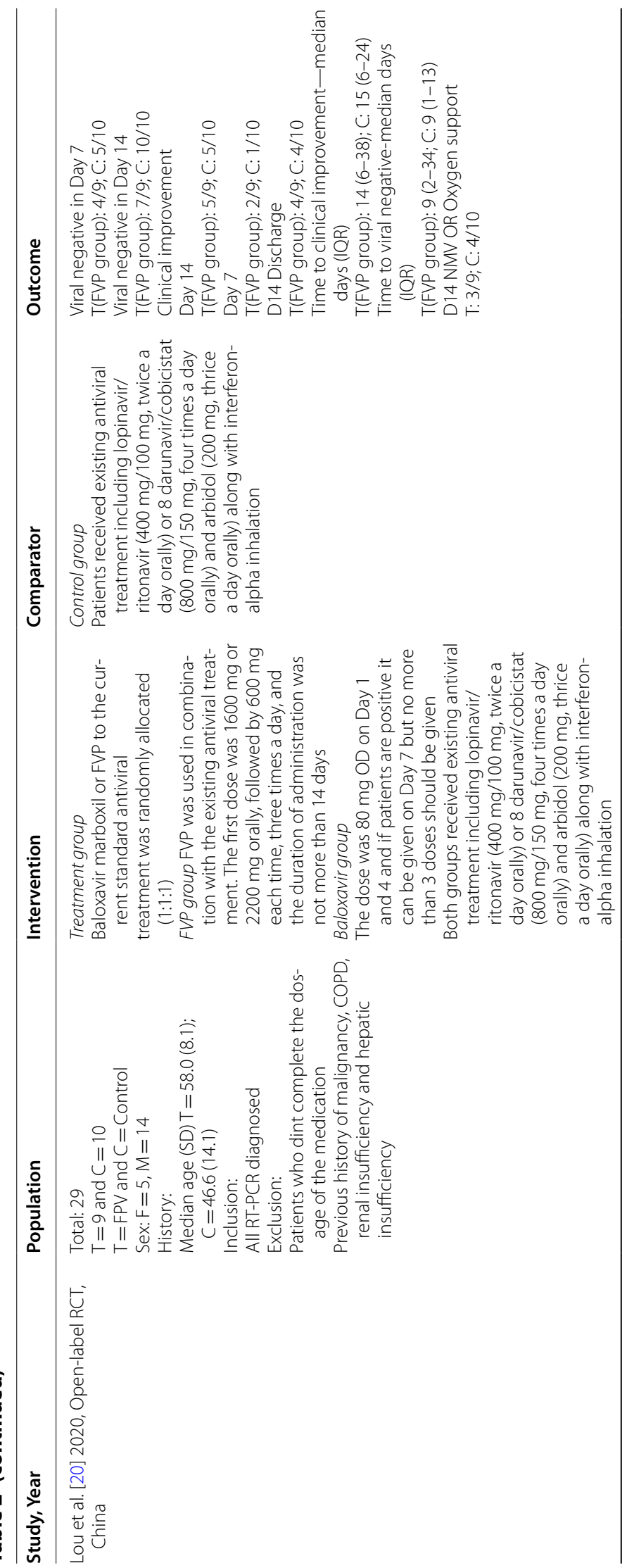




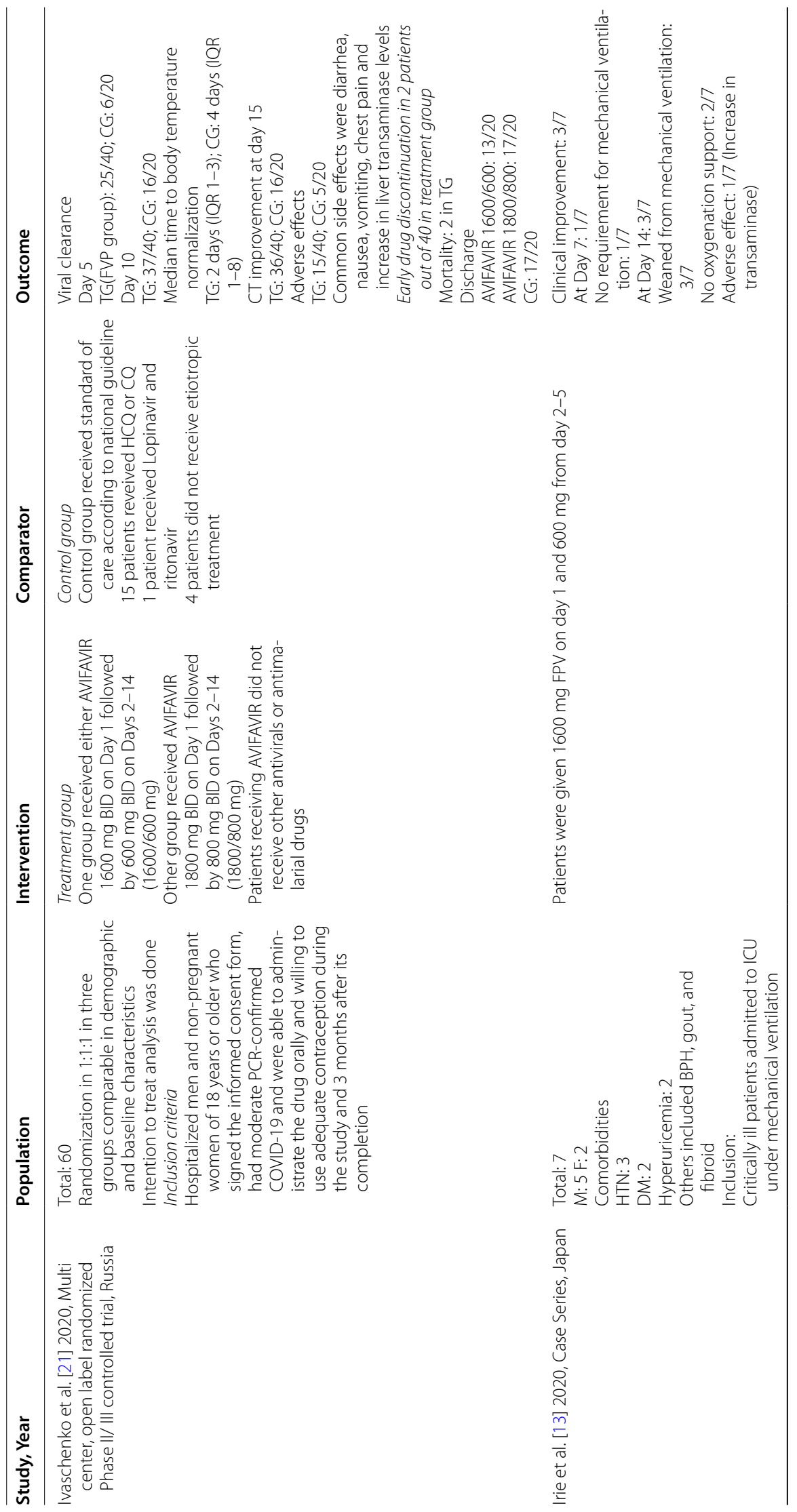




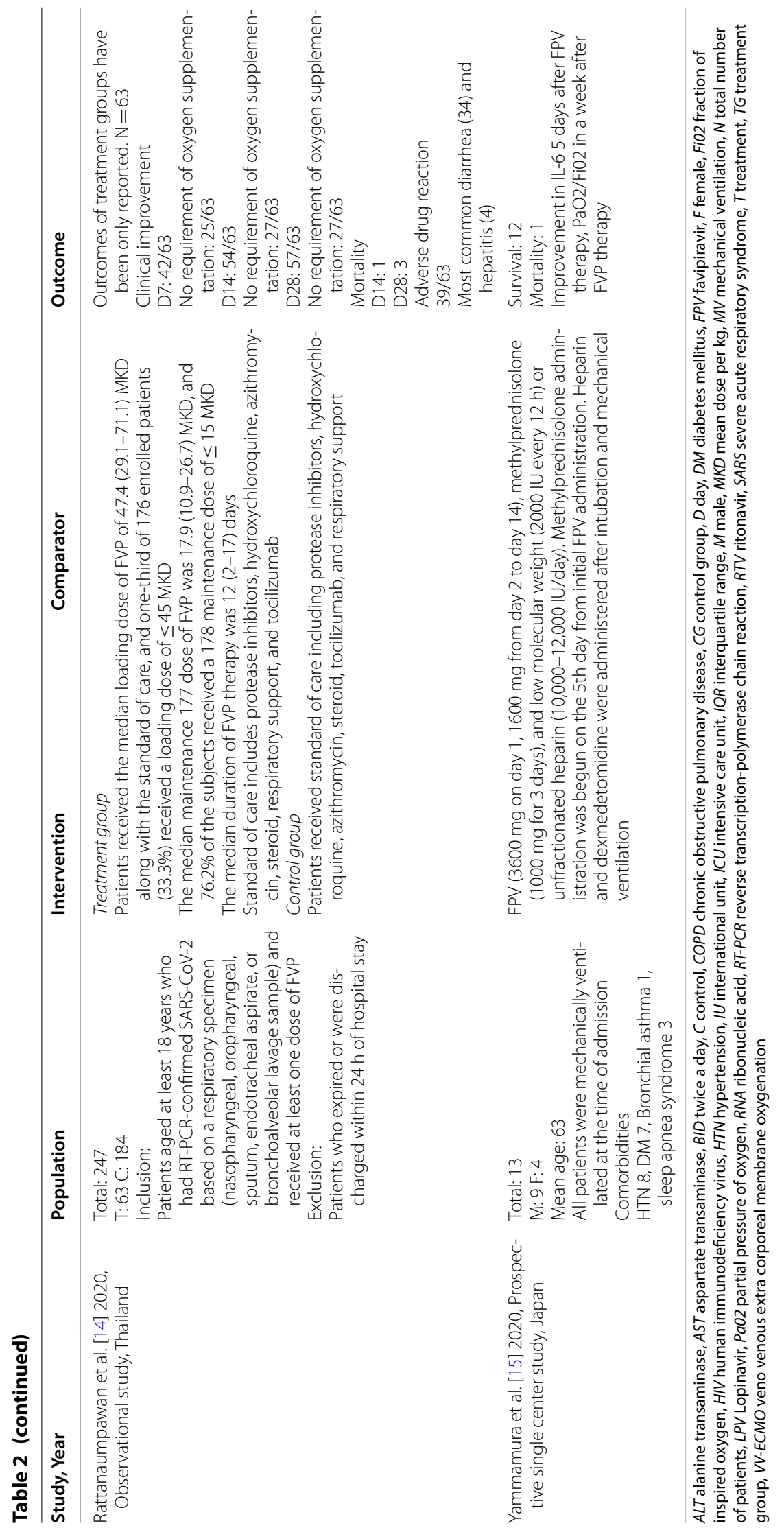


excluded 1284 studies after title and abstracts screening and 52 articles were assessed for full-text eligibility. A total of 43 articles were excluded for definite reasons. We included 9 studies in our qualitative study (Fig. 2). The summary of studies is discussed in Table 2.

\section{Quantitative analysis}

Four studies meet the criteria and are included in the quantitative synthesis. In the present meta-analysis, we have compared findings among randomized/nonrandomized controlled studies to extract outcome on viral clearances, improvements or deteriorations among FVP group in comparison to COVID-19 cases getting other antivirals or SOC, duration to viral clearance, the requirement of non-invasive mechanical ventilation/ oxygen support and adverse effects.

\section{FVP versus other antivirals or SOC only; effectiveness}

Among the treatment groups FVP in addition to SOC versus other antivirals or SOC we have compared the duration of viral clearance (negative RT-PCR) and radiological/ clinical improvement.

Viral clearance The meta-analysis of risk ratios (RR) for FVP in addition to SOC effectiveness compared with other antivirals or SOC using random effect model among randomized and non-randomized studies showed that there were no significant differences between two groups (Day 7: RR 1.13, 95\% CI 0.55 to 2.33; Day 14: RR 1.06, 95\% CI 0.84 to 1.33 ). Also, there is no significant risk difference (RD) for viral clearance between two groups FVP in addition to SOC versus other antivirals or SOC (Day 7: RD 0.06, 95\% CI - 0.34 to 0.45; Day 14: RD 0.03, 95\% CI -0.17 to 0.24 ) (Fig. 3). For heterogeneity, both subgroup assessments inverse variance method and excluding nonrandomized study by Cai et al. [18] showed no significant changes (Additional file 3/Figs. 1 and 2).

Clinical/CT improvement Among three studies, two reported clinical and two reported CT improvement, overall risk ratios (RR) for FVP in addition to SOC effectiveness compared with other antivirals or SOC alone using fixed-effect model showed that there was a significant improvement on FVP groups on both $7^{\text {th }}$ and $14^{\text {th }}$ day of treatment (Day 7: RR 1.25, 95\% CI 1.01 to 1.53; Day 14: RR 1.29, 95\% CI 1.08 to 1.54). Furthermore, there are similar findings on risk difference (RD) between two groups for improvement (Day 7: RD 0.11, 95\% CI 0.01 to 0.22; Day 14: RD 0.19, 95\% CI 0.07 to 0.32) (Fig. 4).

Clinical improvement on the 7 th and $14^{\text {th }}$ day among randomized controlled trials after excluding nonrandomized study by Cai et al. [18] showed slight improvement on favipiravir arm but statistically not significant (Additional file 3/Fig. 3).

\section{FVP versus other antivirals: clinical/CT deterioration}

The meta-analysis on clinical deterioration rate at the end of study duration showed clinical deteriorations is less likely in the FVP treatment group than other antiviral agents though statistically not significant (OR 0.59, 95\% CI 0.30 to 1.14 ; participants $=376$; studies $=3 ; \mathrm{I}^{2}=39 \%$ ) (Fig. 5).

\section{FVP group versus other antivirals or SOC group: Oxygen support or non-invasive ventilation}

Meta-analysis on the oxygen support requirements and non-invasive mechanical ventilation among included randomized studies showed decreased odds of oxygen support among FVP group but it is not statistically significant (OR 0.76, 95\% CI 0.42 to 1.39; participants $=255$; studies $=2 ; \mathrm{I}^{2}=0 \%$ ) (Fig. 6).

\section{Adverse effects}

Meta-analysis comparing adverse effects between the treatment and the control groups showed lesser odds for adverse effect in the treatment arm but of no statistical significance (OR $0.69,95 \%$ CI 0.13 to 3.57; participants $=376$; studies $=3 ; \mathrm{I}^{2}=88 \%$ ) (Fig. 7). Overall adverse effects among randomized controlled trials after excluding non-randomized study by Cai et al. [18] showed slight increase in adverse effects among favipiravir arm but statistically not significant. This may be due to heterogeneity in treatments patients might be taking other than favipiravir or other standard treatment (Additional file 3/Fig. 4).

\section{Duration to convert negative RT-PCR}

Our meta-analysis on negative conversion of RT-PCR demonstrated approximately 5 days (MD $-5.16,95 \% \mathrm{CI}$ -6.95 to -3.37 ; participants $=99$; studies $=2 ; \mathrm{I}^{2}=45 \%$ ) earlier on treatment with FVP group (Fig. 8). Data being subject to moderate heterogeneity sensitivity assessment using the random-effect model showed no significance (MD - 2.16, 95\% CI -13.28 to 8.97). This finding, thus needs to be confirmed by further randomized studies (Additional file 3/Fig. 5).

\section{Clinical trials}

Focusing on the safety and efficacy of FVP for COVID19 treatment along with different parameters, there are 31 RCTs registered in different parts of the world as of 25 August 2020 (Additional file 4) [22]. Five of such trials have recently been completed from Egypt, Iran, and Turkey. Among the registered RCTs, 14 trials are recruiting participants, 6 trials have not yet started 


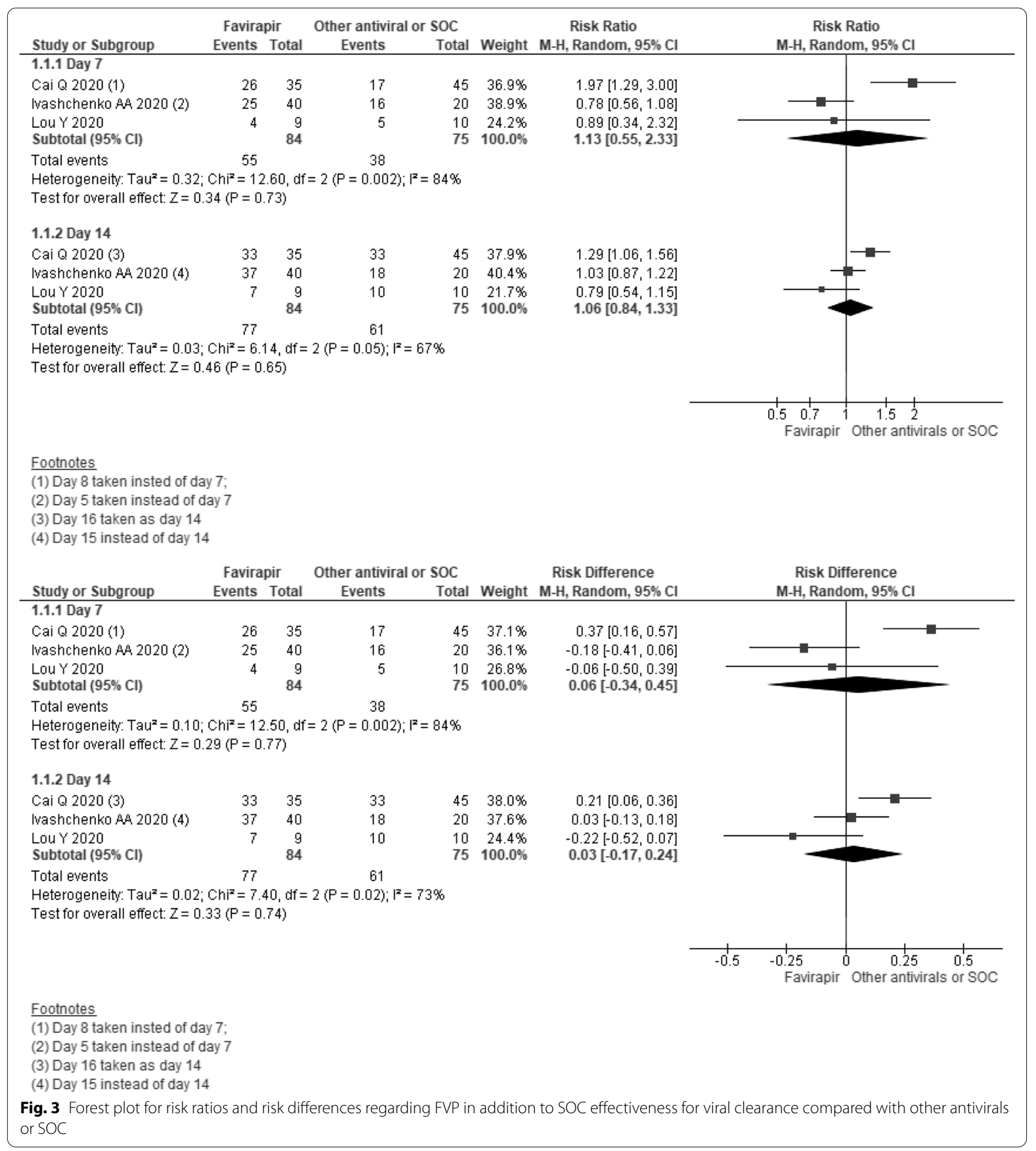

recruiting, and 4 trials are active but not recruiting any participants. One of the trials has been withdrawn thus not been included in this calculation. According to the location provided in 31 trials, a maximum number of trials are regulated by Turkey.

\section{Discussion}

Our meta-analysis was focused on the assessment of the clinical outcome and adverse effects following therapy with FVP because it has emerged as one of the treatments repurposed for COVID-19. Although some 


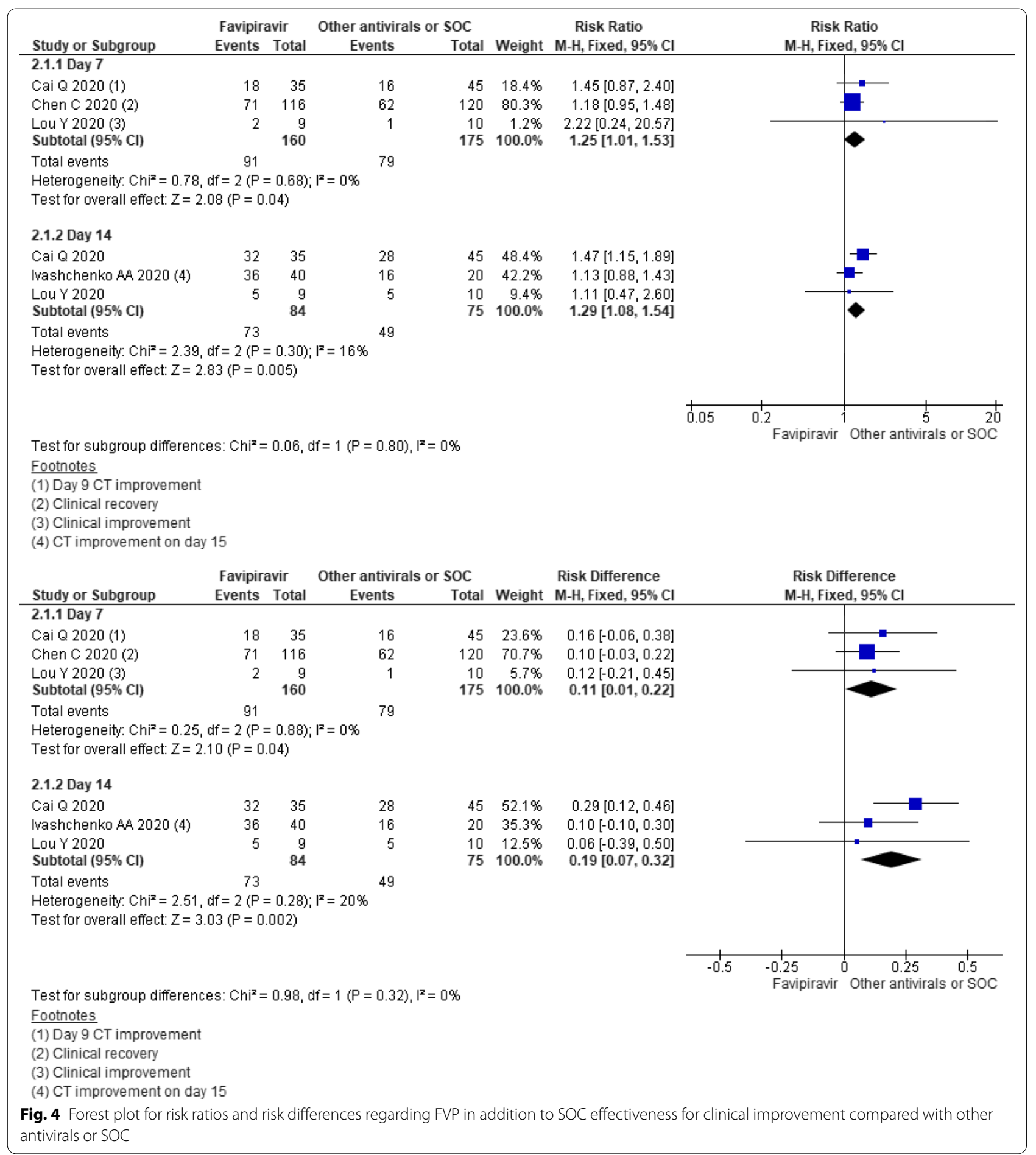

promise has been shown by remdesivir and plasma therapy, the lack of highly efficacious and safe treatment for COVID-19 remains one of the biggest conundrums of the twenty-first century. Our study found that patients had a significant improvement in FVP groups on both the $7^{\text {th }}$ and $14^{\text {th }}$ day of treatment (Day 7: RR $1.25,95 \%$ CI
1.01 to 1.53; Day 14: RR 1.29, 95\% CI 1.08 to 1.54$)$. The clinical deterioration is less likely in the FVP treatment groups than other antiviral agents (OR 0.59, 95\% CI 0.30 to 1.14) following treatments though of no statistical significance. There were no significant differences between the two groups in terms of viral clearance (Day 7: RR 


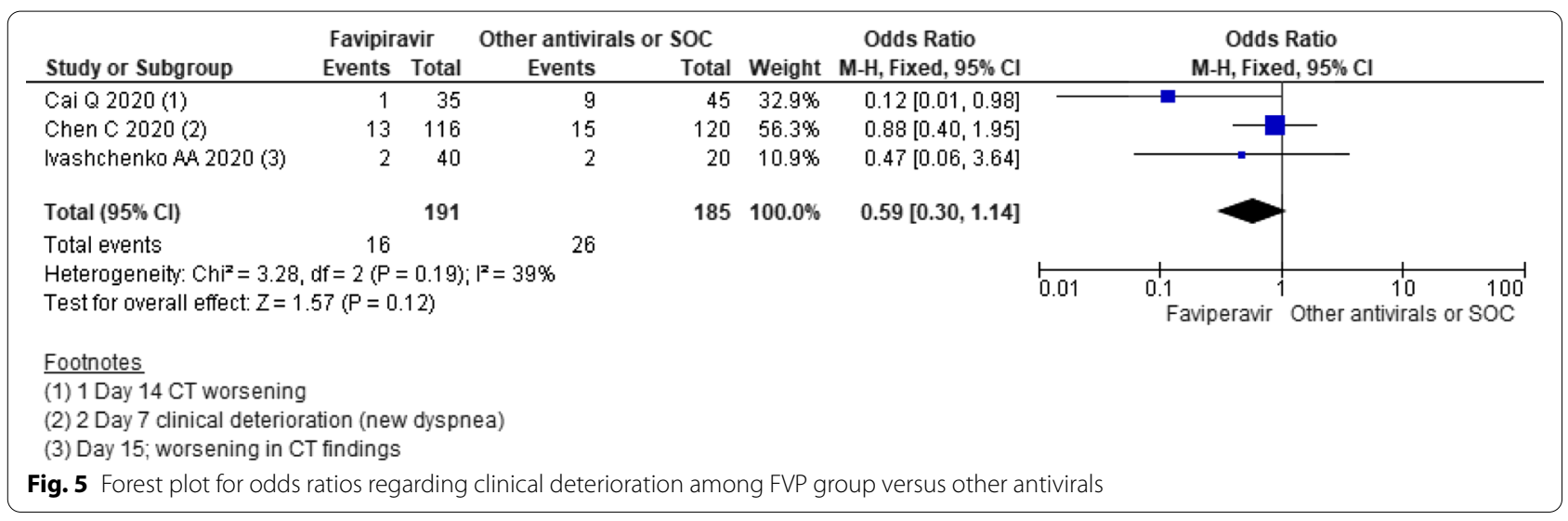

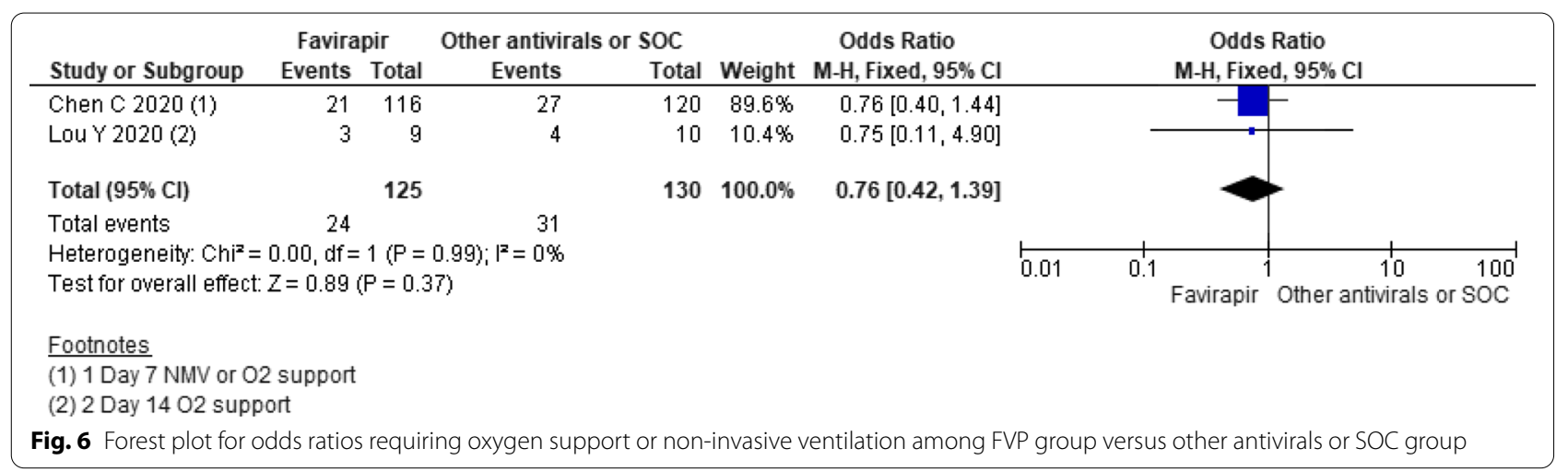

\begin{tabular}{|c|c|c|c|c|c|c|c|c|c|}
\hline Study or Subgroup & \multicolumn{2}{|c|}{ Favipiravir } & \multicolumn{2}{|c|}{ Other antivirals or SOC } & Weight & $\begin{array}{c}\text { Odds Ratio } \\
\text { M-H, Random, } 95 \% \mathrm{Cl}\end{array}$ & \multicolumn{3}{|c|}{$\begin{array}{c}\text { Odds Ratio } \\
\text { M-H, Random, } 95 \% \mathrm{Cl}\end{array}$} \\
\hline Cai 02020 & 4 & 35 & 25 & 45 & $31.8 \%$ & $0.10[0.03,0.34]$ & & $\longrightarrow$ & \\
\hline Chen 02020 & 37 & 116 & 28 & 120 & $36.5 \%$ & $1.54[0.87,2.74]$ & & & - \\
\hline Washchenko AA 2020 & 15 & 40 & 5 & 20 & $31.8 \%$ & $1.80[0.54,5.96]$ & & & \\
\hline Total $(95 \% \mathrm{Cl})$ & & 191 & & 185 & $100.0 \%$ & $0.69[0.13,3.57]$ & & & \\
\hline Total events & 56 & & 58 & & & & & & \\
\hline $\begin{array}{l}\text { Heterogeneity: } \operatorname{Tau}^{2}= \\
\text { Test for overall effect: }\end{array}$ & $\begin{array}{l}86 ; \mathrm{Chi}^{2}= \\
=0.45(\mathrm{P}=\end{array}$ & $\begin{array}{l}=17.19 \\
=0.65)\end{array}$ & $\mathrm{df}=2(\mathrm{P}=0$ & $F^{2}=889$ & & & 0.001 & $\begin{array}{c}0.1 \\
\text { Favipiravir }\end{array}$ & $\begin{array}{|cc|}10 & 1000 \\
\text { Other antivirals or SOC }\end{array}$ \\
\hline
\end{tabular}

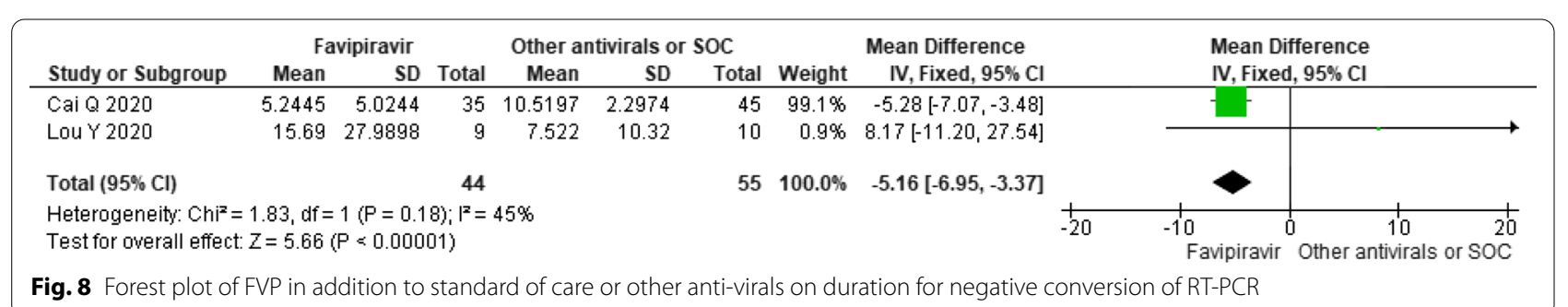


1.13, 95\% CI 0.55 to 2.33; Day 14: RR 1.06, 95\% CI 0.84 to 1.33). There were lesser odds for adverse effect in the treatment group but of no statistical significance (OR 0.69 , $95 \%$ CI 0.13 to 3.57 ). In general, there were tolerable minor side effects like nausea, vomiting, diarrhea and an increase in transaminases and no serious lifethreatening complications following the FVP treatment. The possible side effects can however not be credited to favipiravir alone because the patients in treatment groups were receiving other drugs in 3 trials except the one done by Ivashchenko et al. [21]. As this is the first meta-analysis comparing the clinical outcome and adverse effects among patients receiving FVP compared to standard of care, we could not compare our findings with other meta-analyses.

Although good promise has been shown by FVP, additional randomized double-blind clinical trials are needed to give a definite opinion about the rationale of the drug. We could only include four studies for our quantitative analysis and one of the studies among them was nonrandomized. The sample size was small in our studies which could decrease the power of our study. The duration of treatment and dosages were different among various studies in qualitative analysis. Two of the RCTs that were included for our analysis had a varied duration of treatment as well. Lack of randomization may have led to selection bias in the non-randomized studies. Blinding was not applied to source studies leading to biases. Selective reporting may have been a problem in Chen's study [19] because of the limited observation time frame. It is important to determine the appropriate dose and duration of treatment with FVP because low dose therapy is found to be a bad prognostic factor for clinical improvement and widespread variations in treatment duration among studies and lack of effective plasma concentrations of drug in critically ill patients [13, 14]. Due to the early evidence of potential benefits shown by this drug in clinical improvement as well as imaging improvement, it is necessary to conduct large-scale prospective, double-blind randomized controlled trials or wait for the result of ongoing studies to come. This will embolden the evidences led by our study and eliminate biases so that definitive advice for treatment can be given in the coming days.

\section{Conclusion}

Our study concludes that patients had clinical and radiological improvements following the treatment with FVP in comparison to that of the standard of care though no significant differences on viral clearance, oxygen support requirement and side effect profile. The results of ongoing clinical trials should be obtained to give any definite judgment on whether the treatment with FVP is the best option among antiviral treatments for COVID-19 or not. Till then, our meta-analysis supports judicial use of FVP in clinical settings.

\section{Supplementary information}

Supplementary information accompanies this paper at https://doi. org/10.1186/s12985-020-01412-z.

Additional File 1: Search strategy

Additional File 2: NHLBI Bias of observational and case series

Additional File 3: Synthesis and sensitivity assessment

Additional File 4: Clinical trials

Additional File 5: Prisma checklist

\section{Abbreviations}

ALT: Alanine transaminase; ARDS: Acute respiratory distress syndrome; AST: Aspartate transaminase; C: Control; Cl: Confidence interval; COPD: Chronic obstructive pulmonary disease; COVID-19: Coronavirus disease-19; CT: Computed Tomography; D: Day; DM: Diabetes mellitus; F: Female; FVP: Favipiravir; HIV: Human immunodeficiency virus; HTN: Hypertension; I2: I-squared; ICU: Intensive care unit; IQR: Interquartile range; LPV: Lopinavir; M: Male; MKD: Mean dose per kg; N: Total number of patients; NHLBI: National Heart, Lung, and Blood Institute; OR: Odds ratio; PRISMA: Preferred reporting items for systematic reviews and meta-analyses; RCTs: Randomized controlled trials; RdRp: RNA dependent RNA polymerase; ROB: Risk of bias; RR: Relative risk; RT-PCR: Reverse transcription-polymerase chain reaction; RTV: Ritonavir; SARS-CoV-2: Severe acute respiratory syndrome coronavirus-2; SOB: Shortness of breath; SOC: Standard of care; $\mathrm{T}$ : Treatment.

Acknowledgements

Not applicable

Authors' contributions

DBS, PB, and SK contributed in concept and design, analysis, and interpretation of data. PBS, NP, and PR contributed in literature search, data extraction, review and assisted in analysis. All authors were involved in drafting and revising the manuscript and approved the final version.

Funding

This article did not receive any specific grant from funding agencies in the public, commercial, or any other sectors.

Availability of data and materials

The datasets analyzed during the current study are available from the corresponding author on reasonable request.

Ethics approval and consent to participate

Not applicable.

Consent for publication

Not applicable.

Competing interests

The authors declare that they have no competing interests.

\section{Author details}

${ }^{1}$ Department of Emergency Medicine, Mangalbare Hospital, Morang, Nepal. ${ }^{2}$ Dr Iwamura Memorial Hospital, Bhaktapur, Nepal. ${ }^{3}$ Shree Birendra Hospital, Nepalese Army Institute of Health Sciences, Kathmandu, Nepal. ${ }^{4}$ Nepal Medical College and Teaching Hospital, Kathmandu, Nepal. ${ }^{5}$ KIST Medical College and Teaching Hospital, Lalitpur, Kathmandu, Nepal. 
Received: 7 July 2020 Accepted: 16 September 2020

Published online: 24 September 2020

\section{References}

1. WHO. Novel Coronavirus_China. WHO. 2020. https://www.who.int/csr/ don/12-january-2020-novel-coronavirus-china/en/. Accessed 5 Jul 2020

2. WHO. Coronavirus (COVID-19). WHO. 2020. https://covid19.who.int/?gclid =EAlalQobChMI9ai8sIOz6gIVzQorCh297QloEAAYASAAEgIQ7vD_BwE. Accessed 27 Aug 2020.

3. Singhal T. A review of coronavirus disease-2019 (COVID-19). Indian J Pediatr. 2020:87(4):281-6. https://doi.org/10.1007/s12098-020-03263-6.

4. Gaurav A, Al-Nema M. Polymerases of coronaviruses: structure, function, and inhibitors. Viral Polym. 2019;10:271-300. https://doi.org/10.1016/ B978-0-12-815422-9.00010-3.

5. Yousefifard M, Zali A, Mohamed Ali K, Madani Neishaboori A, Zarghi A, Hosseini M, et al. Antiviral therapy in management of COVID-19: a systematic review on current evidence. Arch Acad Emerg Med. 2020:8(1):e45. https://doi.org/10.1111/ijcp.13557.

6. Sanders JM, Monogue ML, Jodlowski TZ, Cutrell JB. Pharmacologic treatments for coronavirus disease 2019 (COVID-19): a review. JAMA. 2020;323(18):1824-36. https://doi.org/10.1001/jama.2020.6019.

7. Coomes EA, Haghbayan H. Favipiravir, an antiviral for COVID-19? J Antimicrob Chemother. 2020;75(7):2013-4. https://doi.org/10.1093/jac/dkaa171.

8. Liberati A, Altman DG, Tetzlaff J, Mulrow C, Gøtzsche PC, loannidis JP, et al. The PRISMA statement for reporting systematic reviews and metaanalyses of studies that evaluate health care interventions: explanation and elaboration. Ann Intern Med. 2009;151(4):W-65. https://doi. org/10.7326/0003-4819-151-4-200908180-00136.

9. Cochrane. RoB 2.0: a revised tool to assess risk of bias in randomized trials [webinar]. Cochrane Training. https://training.cochrane.org/resource/ rob-20-webinar. Accessed 22 Aug 2020.

10. NHLBI. Study Quality Assessment Tools. National Heart, Lung, and Blood Institute (NHLBI). 2020. https://www.nhlbi.nih.gov/health-topics/study -quality-assessment-tools. Accessed 22 Aug 2020.

11. Çalik BaŞaran N, Uyaroğlu OA, Telli Dizman G, Özişik L, Şahin TK, Taş Z, et al. Outcome of non-critical COVID-19 patients with early hospitalization and early antiviral treatment outside the ICU. Turk J Med Sci. 2020. https://doi.org/10.3906/sag-2006-173.

12. Doi K, Ikeda M, Hayase N, Moriya K, Morimura N, COVID-UTH Study Group. Nafamostat mesylate treatment in combination with favipiravir for patients critically ill with Covid-19: a case series. Crit Care. 2020;24(1):392. https://doi.org/10.1186/s13054-020-03078-z.

13. Irie $K$, Nakagawa A, Fujita $H$, Tamura $R$, Eto M, Ikesue $H$, et al. Pharmacokinetics of favipiravir in critically ill patients with COVID-19. Clin TransI Sci. 2020. https://doi.org/10.1111/cts.12827.

14. Rattanaumpawan P, Jirajariyavej S, Lerdlamyong K, Palavutitotai N, Saiyarin J. Real-world experience with favipiravir for treatment of COVID-19 in Thailand: results from a multi-center observational study. medRxiv; 2020. https://www.medrxiv.org/content/early/2020/07/01/2020.06.24.20133 249.1

15. Yamamura $H$, Matsuura $H$, Nakagawa J, Fukuoka $H$, Domi H, Chujoh S. Effect of favipiravir and an anti-inflammatory strategy for COVID-19. Crit Care. 2020;24(1):1-3. https://doi.org/10.1186/s13054-020-03137-5.

16. Cochrane. Cochrane handbook for systematic reviews of interventions. Cochrane training. https://training.cochrane.org/handbook. Accessed 22 Aug 2020.

17. Wayback Machine [Internet]. Internet archive. https://web.archive.org/ web/20181224162602/http:/www.comp.hkbu.edu.hk/ xwan/media n2mean.html. Accessed 22 Aug 2020.

18. Cai Q, Yang M, Liu D, Chen J, Shu D, Xia J, et al. Experimental treatment with favipiravir for COVID-19: an open-label control study. Engineering (Beijing, China). 2020. https://doi.org/10.1016/j.eng.2020.03.007.

19. Chen C, Zhang Y, Huang J, Yin P, Cheng Z, Wu J, et al. Favipiravir versus arbidol for COVID-19: a randomized clinical trial. medRxiv. 2020. https:// doi.org/10.1101/2020.03.17.20037432

20. Lou Y, Liu L, Qiu Y. Clinical outcomes and plasma concentrations of baloxavir marboxil and favipiravir in covid-19 patients: an exploratory randomized, controlled trial. medRxiv. 2020. https://doi. org/10.1101/2020.04.29.20085761.

21. Ivashchenko AA, Dmitriev KA, Vostokova NV, Azarova VN, Blinow AA, Egorova AN, et al. AVIFAVIR for treatment of patients with moderate COVID-19: interim results of a phase II/III multicenter randomized clinical trial. Clin Infect Dis. 2020. https://doi.org/10.1093/cid/ciaa1176.

22. ClinicalTrials.gov. NIH U.S. National Library of Medicine. 2020. https:// clinicaltrials.gov/ct2/results?cond=COVID-19\&term=Favipiravir\&cntry $=\&$ state $=\&$ city $=\&$ dist $=\&$ Search $=$ Search. Accessed 25 Aug 2020.

\section{Publisher's Note}

Springer Nature remains neutral with regard to jurisdictional claims in published maps and institutional affiliations.
Ready to submit your research? Choose BMC and benefit from:

- fast, convenient online submission

- thorough peer review by experienced researchers in your field

- rapid publication on acceptance

- support for research data, including large and complex data types

- gold Open Access which fosters wider collaboration and increased citations

- maximum visibility for your research: over $100 \mathrm{M}$ website views per year

At BMC, research is always in progress.

Learn more biomedcentral.com/submissions 